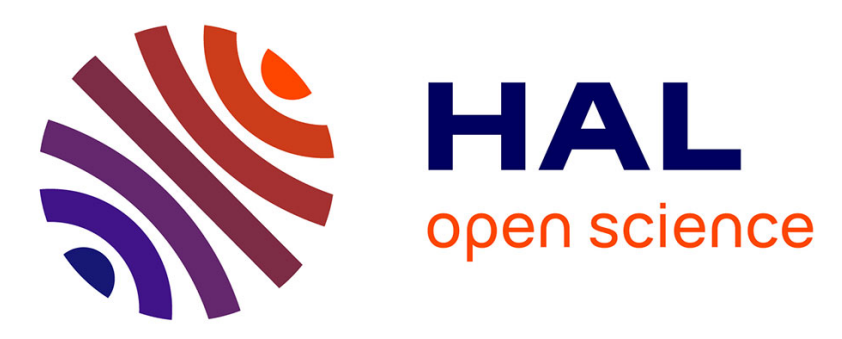

\title{
Design of a valuable Fuel Couple and engine compression ratio for an Octane-On-Demand SI Engine Concept: a simulation approach using experimental data.
}

\author{
Marie Bedon, Misa Milosavljevic, Virginie Morel, Jean-Pascal Solari, \\ Guillaume Bourhis, Roland Dauphin
}

\section{To cite this version:}

Marie Bedon, Misa Milosavljevic, Virginie Morel, Jean-Pascal Solari, Guillaume Bourhis, et al.. Design of a valuable Fuel Couple and engine compression ratio for an Octane-On-Demand SI Engine Concept: a simulation approach using experimental data.. Fuel, 2017, 189, pp.107-119. 10.1016/j.fuel.2016.10.060 . hal-01453360

\author{
HAL Id: hal-01453360 \\ https://hal.science/hal-01453360
}

Submitted on 2 Feb 2017

HAL is a multi-disciplinary open access archive for the deposit and dissemination of scientific research documents, whether they are published or not. The documents may come from teaching and research institutions in France or abroad, or from public or private research centers.
L'archive ouverte pluridisciplinaire HAL, est destinée au dépôt et à la diffusion de documents scientifiques de niveau recherche, publiés ou non, émanant des établissements d'enseignement et de recherche français ou étrangers, des laboratoires publics ou privés. 
1 Design of a valuable Fuel Couple and engine compression ratio for an Octane-On-Demand 2 SI Engine Concept: a simulation approach using experimental data.

3 Marie BEDON a,1 Misa MILOSAVLJEVIC b, Virginie MOREL a, Jean-Pascal SOLARI a, Guillaume

$4 \quad$ BOURHIS b, Roland DAUPHIN b

5 a Aramco Research \& Innovation, 232 Avenue Napoléon Bonaparte, 92500 Rueil-Malmaison, France

6 b IFP Energies nouvelles, 1 et 4 avenue de Bois-Préau, 92852 Rueil-Malmaison, France; Institut Carnot

7 IFPEN Transports Energie

8 Abstract

The efficiency of spark ignition engine is usually limited by the appearance of knock, which is linked to

11 fuel octane number (Research Octane Number - RON and Motor Octane Number - MON). If running the

12 engine at its optimal efficiency requests a high octane number at high load, a lower octane number is only

13 needed at low load.

14 Based on this, the application of so-called Octane On demand concept, whereby the fuel anti knock

15 quality is customized to match the real time requirement of a conventional spark ignition engine has been

16 identified as highly promising.

17 The objective of this study is to define the best fuel couple for the dual fuel "Octane-On-Demand"

18 concept, including a low RON based fuel and an octane booster for minimizing global $\mathrm{CO}_{2}$ tailpipe

19 emissions and the octane booster consumption.

20 The work covers 4 octane boosters: ethanol, reformate, di-isobutylene, and SuperbutolTM, and two fuel

21 baseline: non-oxygenated gasoline RON 91 and naphtha based fuel RON 71.

22 The present activity uses 0D vehicle simulations, based on a M-segment vehicle equipped with an up-to-

23 date 1,6L turbocharged GDI engine, to guide the choice of the fuel couple together with the optimal

24 engine compression ratio. Dedicated inputs, such as engine octane requirement map and fuel anti-knock

25 properties of various blends, are given to properly run the model.

\footnotetext{
${ }^{1}$ Corresponding author. Tel: +31 8826221 99. Email address: marie.bedon@aramcooverseas.com

Page | 1
} 
1 The results show that the trio [10.5 compression ratio and the fuel couple naphtha based RON71 boosted

2 with ethanol] delivers $4.6 \%$ less $\mathrm{CO}_{2}$ emission than the $\mathrm{E} 5$ conventional premium gasoline fuel. This is

3 mainly due to the high RON boosting effect of ethanol, and a low carbon content along with a higher

4 LHV (lower heating value) value of naphtha fuel. RON71 fuel consumption represents $86 \%$ and $76 \%$ of

5 the total volume consumption on NEDC and WLTC, respectively.

6

7 Keywords: Octane requirement, Octane Booster, Research Octane Number, $\mathrm{CO}_{2}$ tailpipe emission, low 8 octane base fuel, 
17 The existing refinery network is not adapted to fulfill this expected imbalance in demand between light

\section{Introduction and background}

The worldwide annual demand for transport energy is increasing rapidly, driven by global economic and population growth, especially in non-OECD countries (Organization for Economic Co-operation and Development). Today, around 95\% [1, 2] of all transport energy comes from petroleum based liquid fuels, mainly manufactured in refineries. Even though promising alternatives to conventional fossil fuels exist today (e.g. biofuels, fuel cells, electric vehicles, etc.), many studies indicate that around $90 \%$ of transport energy will still be derived from petroleum in 2040 [1, 2, 3].

However, this predicted growth in oil demand is mainly driven by the expansion of commercial transport activities, including heavy-duty, air, marine, and rail traffic which all use distillate fuels like diesel, kerosene and marine fuels [2-5]. The projected demand (Fig. 1) of light fuel (gasoline) is to remain flat, since technological improvements (engine downsizing, hybridization, etc.) are expected to enable considerable fuel economy savings. This will ultimately lead to an abundance of lighter-end oil fractions like naphtha, directly derived from the atmospheric crude oil distillation process.

distillates and heavier fuels and considerable investments in refinery conversion units will be necessary. In addition to economic considerations, more complex refinery process units also imply more $\mathrm{CO}_{2}$ emissions. This scenario will probably lead to an unwanted increase in the well-to-tank carbon footprint of petroleum-based fuels.

In recent years, legislation for reducing $\mathrm{CO}_{2}$ emissions emitted by passenger cars and light duty vehicles has been initiated in Europe. The 2020 target of $95 \mathrm{~g} \mathrm{CO}_{2} / \mathrm{km}$ is very challenging and will require further 
1 technology improvements. To achieve this target, a lot of effort over the past decade has been put in place

2 to develop compression ignition engine technology, given its higher intrinsic efficiency compared to

3 spark-ignition engines. However, recent improvements in gasoline engine efficiency, mainly driven by

4 the introduction of downsizing and its associated technologies, have demonstrated that there is still

5 opportunity for this technology to contribute to the reduction of $\mathrm{CO}_{2}$ emissions.

6 The efficiency of a spark ignition engine is often limited by the knock phenomenon which is intrinsically

7 related to auto ignition properties of the fuel, commonly measured by RON (Research Octane Number),

8 where a higher RON indicates better anti-knock properties.

9 Indeed, without knock, the combustion phasing can be tuned optimally, regardless of the engine speed

10 and load, leading to better cycle efficiency. Moreover, engine compression ratio can be increased for a

11 further improvement in thermodynamic efficiency.

12 Nevertheless, a high RON is not necessary over the entire engine map, especially when running at low 13 load.

15 Based on this principle, having a variable fuel RON quality and adjusting it as any other engine operating

16 parameter has been identified as a promising engineering approach to increase the global engine

17 efficiency and consequently reduce $\mathrm{CO}_{2}$ tailpipe emissions.

19 Motivated by the existing energy landscape and outlooks, and with the initiative to promote a responsible

20 use of petroleum products in the transportation sector, Saudi Aramco is pursuing collaborative research

21 programs with IFP Energies nouvelles to develop and demonstrate novel fuel/engine solutions, capable of

22 addressing modern technological and environmental challenges. One of the joint research initiatives aims

23 at developing the "Octane on Demand" (OOD) concept on an SI engine by adapting the octane level of 
1 the fuel on an as-needed basis. This concept relies on a dual fuel system, using a low RON base fuel and

2 an octane booster, blended in the cylinder in real time.

4 The present work is intended as a step toward proving the feasibility of the OOD concept. The objective

5 is to identify the best combination of base fuel, octane booster, and engine compression ratio, to minimize

6 both $\mathrm{CO}_{2}$ emissions and octane booster consumption, which is considered as a high value product. In this

7 respect, a 0D vehicle simulator has been built and validated, using the following results as relevant inputs:

9 Bourhis et al. [6] characterized the octane requirement of a 1.6L turbocharged DI multi cylinder gasoline 10 engine for three different compression ratios, using TRF (Toluene Reference Fuels).

11 Rankovic et al. [7] identified experimentally, based on CFR engine measurements, RON blending rules of 12 a complete fuel matrix when blending low RON based fuel (two baseline) with various octane boosters 13 (four boosters).

14

\section{Simulation Tool: set-up, validation and calculation matrix}

\section{$17 \quad 2.1$ AMESIM simulator set-up}

18 In order to identify the benefit of the OOD concept on a vehicle over various driving cycles, a OD 19 simulator was built using LMS.Imagine.Lab Amesim ${ }^{\circledR}$ platform [8]. LMS Amesim DRIVE library [9],

20 developed by IFP Energies nouvelles, allows to build a complete vehicle physical model as well as its

21 environment with the road profile, car dynamics, gearbox and the driver. The internal combustion engine

22 model is based on fuel consumption map reading and the correction factors dependent on the driver 
1 solicitations as well as on the thermal conditions of the engine (as the real engine control unit). With that

2 method the car model reproduces the resistive load taking into consideration its wheel and aerodynamic

3 characteristics, wind speed and direction as well as the road slope. That resistive force is sent to the

4 gearbox which adapts the engine speed to the desired vehicle velocity. Bearing in mind its gear efficiency

5 and inertia, the torque demand and speed are communicated to the engine. Following the specified speed

6 profile and norm specified gear shifting, the driver model requests the engine load to satisfy the speed

7 request.

8 0D vehicle simulation based on engine bench and chassis-dyno tests allows the concept evaluation 9 upstream of any prototype, thus shortening the project duration and decreasing the costs.

11 Simulation results should provide the best compromise among the different internal combustion engine

12 (ICE) compression ratios and dual fuel combinations in order to take the best of the low octane fuel to 13 improve engine efficiency and to decrease $\mathrm{CO}_{2}$ emissions.

14 Amesim DRIVE library was used to build the vehicle model based on M-segment vehicle (Citroën Grand 15 C4 Picasso) with the associated longitudinal dynamics.

16 Vehicle parameters are given in Table 1, and overall view of the simulator sketch in Fig 3.

17 The internal combustion engine dedicated to the OOD concept is a GDI 1.61 turbocharged engine, 18 modeled by its fuel consumption map coming from engine tests with three engine compression ratios (7.5, 1910.5 - stock version and 12:1) running on four octane boosters (reformate - ethanol - DIB 20 SuperButolTM) and two base fuels (RON71 and RON 91 - see paragraph 3.1). At this stage of the 21 program, the simulations did not consider cold operation and the driving cycles were run with engine 22 coolant temperature of $90^{\circ} \mathrm{C}$. A specific IFP-DRIVE library engine model was developed in order to take 23 into account dual-fuel concepts. 
1 The engine was linked to a vehicle drivetrain by a 6-gear manual gearbox modeled by the gear ratios and

2 gear efficiencies. Gearbox parameters are given in Table 2

5 In order to cover a large vehicle operating range and test the concept in various dynamic conditions, two

6 driving cycles were chosen: the New European Driving Cycle (NEDC) as current normative cycle, and

7 the worldwide harmonized Light duty driving Test Cycle (WLTC) as expected future normative cycle

8 (presented in paragraph 2.3).

9 The driving cycles target was followed by a driver model based on a Proportional-Integral-Derivative 10 regulator (PID). This element manage load request and brake command to follow the vehicle speed 11 specified by the driving cycle.

12 The simulator was also able to consider the ambient and road conditions as wind speed, air density and 13 temperature as well as the road slope and the vehicle load. In the normative cycles, the conditions was 14 considered as standard (ambient temperature: $20^{\circ} \mathrm{C}$ and air density: $1.185 \mathrm{~kg} / \mathrm{m} 3$ ) without any 15 supplementary vehicle load nor wind speed.

16 Finally, constant auxiliary power taken from the engine was integrated in the simulator in order to 17 consider electric consumers.

\subsection{Simulator validation}

20 Before assessing the potential of a new dual fuel concept, the vehicle model needs to be preliminary

21 validated based on its in-field production version. To do so, an M-segment vehicle run on a roller bench

22 over the NEDC driving cycle was used in order to fine tune the vehicle gear train and thus get the right 
1 torque demand and engine speed. Vehicle stopped, experimental engine load was fitted to find auxiliary

2 torque demand. (See Fig. 2)

3 Engine to vehicle speed experimental and simulation fitting was done by the wheel dynamic radius as the

4 gear train ratios are known. Engine torque demand in steady conditions was adjusted with gear

5 efficiencies. In vehicle speed transients, powertrain inertia was set in order to achieve similar torque

6 overshoots.

8 The maximal engine speed and torque fitting error was found at the very beginning of the transient and

9 was due to the driver controller anticipation capability and its controller sensitivity. Nevertheless, engine 10 speed error remained under $200 \mathrm{rev} / \mathrm{min}$ during light transients. The torque demand error remained under 115 N.m out of harsher transients. In steady state operation, the error was near zero for speed and torque. 12 Zero load operation showed that electric consumers request $100 \mathrm{~W}$. These results were considered as 13 acceptable for the purposes of the study.

14 The fuel consumption over the NEDC cycle for this specific vehicle is announced by the car maker at 6.0 $15 \mathrm{~L} / 100 \mathrm{~km}$. That result is obtained when the vehicle macerates at $20^{\circ} \mathrm{C}$ prior testing, and consequently with 16 a cold powertrain operation (engine over-consumes during heating process). The simulator, which ran 17 with the engine at $90^{\circ} \mathrm{C}$ (coolant temperature) over the entire cycle, consumes $5.9 \mathrm{~L} / 100 \mathrm{~km}$ of SP95 E5 18 fuel (reference fuel), which is equivalent to $138 \mathrm{gCO}_{2} / \mathrm{km}$.

19 These results demonstrated the validity of the simulator and will be used as the reference for further 20 comparisons. 
1 The simulations were performed on two driving cycles (Fig.4 \& Fig. 5). WLTC cycle: a series of data points

2 representing the speed of vehicle versus time). The first cycle is the homologation cycle commonly used in

3 Europe (NEDC) (Fig.4).

4

5 The second one is the upcoming homologation cycle, referred to as WLTC (Worldwide harmonized Light

6 duty driving Test Cycle) (Fig. 5). WLTC is a more severe cycle than its predecessor NEDC, especially

7 with regards to transient conditions and is considered to be more representative of real driving conditions.

8 As a result, when evaluating the benefit in fuel consumption and CO2 emissions of the OOD concept,

9 results derived from the simulation on this cycle will be given greater weight.

1124 engine/fuel configurations (detailed in the next paragraph) were run over the two driving cycles (Table $123)$

\section{3. Model inputs: fuel behavior \& engine octane requirement map}

\section{$17 \quad 3.1$ Fuel presentation}

18 As mentioned in the introduction, developing the Octane on Demand concept requires an appropriate

19 selection of octane enhancers and a deep understanding of their behavior when blended with a low octane 20 base fuel. Table 4 gives the properties of the fuels considered. 
2 Non-Oxygenated Gasoline (NOG) RON 91 corresponds to the exact RON of the non-oxygenated gasoline 3 used in this study as low RON gasoline.

4 Naphtha-based fuel RON 71, which is a blend of pure straight-run, desulfurized whole boiling range 5 naphtha RON 53 and non-oxygenated gasoline RON 91 with the respective volume rates of 56\% and $644 \%$. Naphtha is a generic term describing the fraction of crude oil distilled within the $30-180^{\circ} \mathrm{C}$ range. It 7 is composed of C5 to C11 hydrocarbons and has a low RON, roughly within the 40-70 range. It is a 8 refinery product that could potentially be beneficial for reducing the $\mathrm{CO}_{2}$ footprint of fuel from well-to9 tank as a result of lower refinery processing when compared to commercial gasoline. Naphtha is only 10 processed in the crude atmospheric distillation tower and undergoes light hydrodesulphurization, in 11 contrast to commercial gasoline which is a blend of streams coming from different conversion units such

12 as catalytic reformers, Fluid-Catalytic-Cracking (FCC), Isomerization or Alkylation, all being energy 13 intensive and costly processes dedicated to increase the octane number of the fuel. From the perspective 14 of reducing CO2 emissions from tank-to-wheel, compared to gasoline fuel, naphtha also presents an 15 intrinsic benefit. Indeed, with a higher $\mathrm{H} / \mathrm{C}$ ratio along with a higher energy content (Lower Heating 16 Value, LHV), naphtha can directly lead to tailpipe CO2 reduction benefits. Depending on the process unit 17 parameters, naphtha can theoretically deliver a $\mathrm{CO} 2$ benefit of 4 to $7 \%$ assuming the same engine 18 efficiency (Fig. 6). With these considerations, naphtha is identified as a promising low RON base fuel.

20 Octane boosters:

21 1. Reformate (RON 111) is the main product of catalytic reforming, a refinery process that transforms 22 heavy naphtha (80-180 ${ }^{\circ} \mathrm{C}$ boiling range) into a pool rich in aromatics (mainly $\mathrm{C} 7$ to $\left.\mathrm{C} 10\right)$. In the 23 present study, a generic Reformate has been used with $97 \mathrm{~m}$. \% of aromatic molecules (C7 to C10). 
1 Compared to ethanol and SuperButol ${ }^{\mathrm{TM}}$ (presented below), Reformate has the highest RON, density 2 and LHV (in MJ/L), but the lowest $\mathrm{H} / \mathrm{C}$ ratio.

3 2. Ethanol (RON 108), is a well-known and widely used octane booster. Today, ethanol is present on the 4 worldwide fuel market (mainly US, Europe and Brazil). Currently, most conventional gasoline 5 engines are compatible with European unleaded RON95-E10 fuel which contains up to 10\%vol 6 ethanol blended with gasoline. Ethanol allows a natural $\mathrm{CO}_{2}$ benefit in a combustion process because 7 of its H/C ratio, despite its low LHV compared to conventional oil-derived fuels. Moreover, ethanol is

8 a renewable energy fuel produced by a biochemical process and hence delivers a reduced fuel CO2 9 footprint when blended with gasoline. [9,10,12].

103 . SuperButol ${ }^{\mathrm{TM}}$ (RON 107), is an octane booster which is produced in a conversion process patented by 11 Saudi Aramco [8, 9] by simultaneously dimerizing and hydrating a hydrocarbon stream rich in C4 12 olefin molecules. In terms of composition, SuperButolTM consists of variable proportions of butanols 13 and diisobutylenes (DIB), with 2-butanol being the major component. Butanols have the advantage of

\section{$24 \quad 3.2$ - RON Characterisation of blended fuels}

25 RON measurements on CFR engine tests were performed to define anti-knock properties of a wide range 26 of fuel mixtures for various incorporation rates of octane booster [7]. The results are displayed in Fig. 7. 
1 Among multiple results, it is worth mentioning that for almost all blends, the effect of incorporating any

2 of the studied boosters on a volumetric basis is non-linear, with the exception of reformate. In addition,

3 the slope of RON evolution decreases with the incorporation rate, suggesting an improved 'boosting'

4 effect at low concentrations of octane booster. Ethanol exhibits the strongest non-linear "boosting" effect,

5 whilst reformate has the lowest one, in spite of its highest RON value.

7 These results also highlight the interesting potential for using a low RON base fuel. Indeed, starting with

8 a RON of 71, an addition of 30 vol. \% of ethanol is enough to almost reach the same anti-knock

9 properties as a commercial RON 95 unleaded gasoline. The RON reached with 60 vol. \% of ethanol is

10 roughly the same whether using either a RON 71 or a RON 91 base-fuel. This shows the advantage and

11 the potential of using less processed fuels.

13 As a conclusion, relatively high RON can be achieved by mixing small amounts of octane booster with a 14 low RON base fuel, due to the non-linear behavior of RON with respect to the booster incorporation rate.

\section{3 - Engine octane requirement map with TRF}

17 In previous work, Bourhis et al. [6] characterized the anti-knock (or RON) requirements of a state-of-the18 art turbocharged SI engine. Dedicated tests were performed on this engine using surrogate fuels, referred 19 to hereafter as TRF (Toluene Reference Fuels). RON was widely varied from 71 to 111 and tested on 20 three different compression ratios of 7.5, 10.5 and 12.

21 Fig. 8, Fig. 9, Fig.10 represent the octane requirement maps of the engine for the three compression ratios,

22 respectively CR7.5:1, CR10.5:1, CR12:1. On these maps, each iso-line represents the load where the

23 engine starts knocking for a given RON. The black dots represent the engine operating points over the

24 NEDC driving cycle. The figures show that:

25 - Regardless of the engine compression ratio, the engine can be run at its optimal efficiency on its entire 
1 - The engine optimal efficiency can be maintained over a significant operating area at low and mid load

2 with only pure RON 71.

3

4 4. Results and discussion

5

\subsection{Octane requirement over driving cycles: towards demonstration of the OOD concept value}

7 Fig. 11 and Fig. 12 depict the octane requirement of the engine when running at its optimal efficiency, over

8 the two driving cycles NEDC and WLTC, for the three tested compression ratios. The black line

9 represents the instantaneous octane requirement as a function of time while the green dashed lines depict

10 volumetric average of the octane requirement during the whole driving cycle. Finally, the red dashed line

11 positions the RON 95 of standard commercial gasoline. The pie graphs represent the required ratios

12 (\%vol.) of different octane ranges.

14 From these figures, it is interesting to note that:

15 - On average, the driver's RON requirement is significantly lower than the octane quality of a standard 16 RON 95 commercial gasoline fuel: green dashed lines (the average RON need) are always well below 17 the (commercial RON 95 gasoline value (red dashed line).

- $\quad$ With CR 7.5:

- 71 RON fuel represents roughly 100\% of fuel consumed at optimal combustion phasing on the NEDC cycle and 94\% on the WLTC cycle;

- $\quad$ The RON needed to run the engine at optimal spark advance on WLTC does not exceed 95, even during the most demanding accelerations.

- With the CR 10.5 (stock engine configuration): cycle and $44 \%$ on the WLTC; 
- $\quad 80 \%$ of NEDC cycle can be ran at optimal spark advance with a fuel having a RON under 90.8 whereas $61 \%$ of WLTC cycle runs with RON under 90.8 .

- $\quad$ On the WLTC cycle, RON above 95 is only necessary to perform the most severe transient conditions at optimal combustion phasing. RON95 is rarely requested on the NEDC cycle.

\section{- With CR 12:}

- 71 RON fuel represents $50 \%$ of the fuel consumed at optimal combustion phasing on the NEDC cycle and $40 \%$ on the WLTC cycle;

- $\quad$ On both cycles, the full range of RON is used to maintain the optimal combustion phasing. However, $89 \%$ and $74 \%$ of fuel consumed on NEDC and WLTC respectively have a RON lower or equal to 97.5 .

These simulation results point out the over RON quality of commercial gasoline fuel over a significant part of homologated or “real” driving cycles when driving an M-segment passenger car. Most of the time, a lower RON 71 fuel is sufficient to run the engine at its optimal efficiency. A fuel RON95 value is only needed for specific peak driver’ request.

\subsection{Selection of the best compression ratio (CR)}

The complete $\mathrm{CO}_{2}$ optimization of the OOD concept implies to define the best fuel couple (base fuel and booster) and the engine design through the compression ratio specification, as a whole.

Fig. 13 represents $\mathrm{CO}_{2}$ emissions over the NEDC and WLTC cycles, for all fuel combinations, and the three different compression ratios.

It can be seen that, regardless of the cycle and the fuel combination used, cycle $\mathrm{CO}_{2}$ emissions are minimized with CR 10.5 and CR12 and maximized with CR7.5 (Fig. 13). This is consistent with the previous analysis directly made from engine test bed results with TRF [6]. Indeed:

- When increasing the CR 7.5 to 10.5, significant decreasing of CO2 emissions are reported (8g average). Actually, the engine BSFC (Brake Specific Fuel Consumption) is increased over the 
entire map as illustrated in Fig. 14 mainly due to a better theoretical efficiency (in the reference Beau de Rochas cycle, higher the CR, higher the theoretical efficiency).

- When increasing the CR 10.5 to 12 , CO2 benefits are still measured ( 1-2 g of benefits) but significantly lower compared to the gap shown between CR7.5 and CR10.5.

Indeed, the analysis of BSFC gap between CR10.5 and CR12, as illustrated Fig. 15, highlights that:

- At load $>20 \%$ of maximum BMEP, increasing the CR from 10.5 to 12 leads to BSFC benefits (CR effect on the Beau de Rochas cycle),

- At very low load ( $<20 \%$ of maximum BMEP), on the points the "driving cycles" mainly operate, increasing CR from 10.5 to 12 leads to a lower engine efficiency. The major reason behind that is mainly attributable to the CR12 piston shape that is less flat than the CR10.5 one. Flame propagation is altered, which slows down the combustion speed, and wall heat losses are increased as well as exhaust temperature. Detailed and relevant explanation can be found in [6].

In light of these findings, engine in a CR10.5 configuration has been detected as the most relevant engine configuration due to a competitive fuel consumption (global $\mathrm{CO}_{2}$ emissions) and reasonable octane booster consumption. Moreover, the fact that the CR 10.5 already exists as a basis of comparison (stock engine and stock vehicle tests), it allows to assess the impact of the OOD concept only, with no other hardware configuration change. As a conclusion, the CR 10.5 has been identified as the best CR for the Octane On Demand program.

\subsection{Selection of the most valuable fuel combination with CR 10.5}

Fig. 16 represents the consumption of the base fuels and octane boosters for each fuel combination, over the NEDC and WLTC cycles. Overall cycle $\mathrm{CO}_{2}$ emissions are also reported. Fig. 17 represents the percentage of booster use on each driving cycle for each couple of fuels. 
From these figures, it can be noticed that:

3 - Regardless of the octane booster and the driving cycle, naphtha-based fuel offers roughly $1 \%$ less

$4 \quad \mathrm{CO}_{2}$ emissions (except with reformate that has a very high carbon content). This is partly related to

5 the fuel's higher H/C ratio and LHV (low carbon content compared to gasoline), and confirms the

$6 \quad$ high potential of using low RON naphtha-based fuel as a base fuel.

7 - In all configurations, less base fuel is consumed with RON 71 naphtha-based fuel than with RON 91

8 non-oxygenated gasoline. This is due to the fact that when a lower RON base fuel is used, more

9 octane booster is needed to fulfill the mean octane requirement.

10 - The comparison of the global (base fuel + octane booster) fuel consumptions between RON 91 non-

11 oxygenated gasoline and RON 71 naphtha-based fuel highly depends on the energy content of their

12 associated octane booster. If the octane booster has a higher energy content than the base fuel, the

13 global fuel consumption will decrease when lowering the RON of the base fuel (because it shifts the

14 consumption of base fuel towards octane booster which has a higher energy content in this case). This

15 is typically the case when reformate is used as an octane booster. Conversely, if the octane booster

16 has a lower energy content than the base fuel, the global fuel consumption will increase when

17 lowering the RON of the base fuel. This is the case with ethanol and SuperButol ${ }^{\mathrm{TM}}$.

- For both NEDC and WLTC driving cycles, ethanol and DIB, combined with RON 71 naphtha, produce the lowest $\mathrm{CO}_{2}$ emissions. (See Fig. 16). The global volumetric fuel consumption (including base fuel and booster) is slightly higher when using ethanol (NEDC: naphtha/ethanol (6.0 L/ $100 \mathrm{~km})$ - naphtha/DIB (5.8L/100 km) - WLTC: naphtha/ethanol (6.1 L/ $100 \mathrm{km)} \mathrm{-} \mathrm{naphtha/DIB} \mathrm{(5.6L/100}$

$23 \mathrm{~km})$ ). This is related to the lower density and LHV of ethanol.

24 - Because of its high octane boosting power, ethanol has the lowest rate of booster consumption on 25 both driving cycles (Fig. 17). Then, fig. 17 shows that the rate of RON71 consumption when blended 
1 with ethanol represents respectively $86 \%$ and $76 \%$ of the total volume consumption on NEDC and 2 WLTC.

3 - Finally, RON71/Ethanol offers $4.4 \% \mathrm{CO}_{2}$ benefit when compared to E5 fuel reference (138 g/km on 4 the NEDC cycle compared to $132 \mathrm{~g} / \mathrm{km}$ and $136 \mathrm{~g} / \mathrm{km}$ on WLTC cycle compared to $130 \mathrm{~g} / \mathrm{km}$ ). In 5 that case, this gains could be representative of OOD concept.

6

7 Based on these results, and also considering the availability of ethanol on the market, naphtha RON 71

8 along with ethanol is identified as the most valuable fuel combination for the OOD concept. This fuel

9 couple allows minimizing $\mathrm{CO} 2$ emissions and maximizing the benefits of using a less process oil-based 10 fuel.

11

12 


\section{Summary and Conclusion}

2

3

The present study is an additional step towards the assessment and the validation of the Octane on Demand concept, in which spark ignition (SI) engine is operated in a dual-fuel mode, with an adjustable octane quality. In a previous paper, Rankovic et al. [7] already showed the great interest of using a RON 71 naphtha-based fuel with ethanol, the latter having a strong specific octane boosting effect as soon it is incorporated in a low RON fuel. In another paper, Bourhis et al. [6] characterized the octane requirement of a modern turbocharged SI engine and showed that the engine can be run at MBTE conditions over a significant area of the engine map with RON71.

Using these past results as inputs, 0D driving cycle simulations, based on an M-segment vehicle, are performed over the NEDC and WLTC homologation cycles. Two base fuels (Non-Oxygenated-Gasoline RON91 and naphtha-based fuel RON 71), and four octane boosters (ethanol RON 108, Reformate RON 111, DIB RON104, and Superbutol ${ }^{\mathrm{TM}}$ RON 107) are considered. Additionally, three different engine configurations are evaluated (compression ratios 7.5, stock 10.5 and 12), leading to a total amount of 24 fuel / engine configurations tested.

Simulation results show that $\mathrm{CO}_{2}$ tailpipe emissions are minimized when running with the stock engine CR $10.5\left(\mathrm{CO}_{2}\right.$ emissions are very close with CR 12), regardless of the fuel combination. Due to the intrinsic fuel properties related to $\mathrm{H} / \mathrm{C}$ ratio and the energy content, naphtha-based fuel RON 71 offers the lowest $\mathrm{CO}_{2}$ emissions among the two base fuels, whatever the octane booster (except with reformate). Ethanol, with its highest octane boosting effect when mixed with naphtha-based fuel RON 71, minimizes both overall $\mathrm{CO}_{2}$ emissions and the octane booster consumption ratio. With the optimal configuration [CR 10.5; naphtha-based fuel RON 71 as the base fuel; ethanol as the octane booster], the OOD concept offers a CO2 benefit of $4.5 \%$ over both driving cycles when compared to the reference case with E5 and $76 \%$ vol. of less processed RON71 fuel is sufficient to run permanently the engine at it optimal efficiency 
1 conditions on WLTC. Further optimization regarding the right level of downsizing/ upsizing of the engine

2 altogether its design itself are currently being conducted to better improve CO2 benefits and maximize

3 base fuel consumption.

4

\section{Acknowledgements}

6 The authors would like to acknowledge collaborators from IFP Energies nouvelles and Aramco Research

7 \& Innovation in Paris for their fruitful inputs while performing this work.

8

9 


\section{Highlights}

3

- Identification of the most promising engine configuration, low octane base fuel, and octane booster while minimizing $\mathrm{CO}_{2}$ emissions.

- $0 \mathrm{D}$ simulation approach using experimental data helps understanding both engine and

- Naphtha-based fuel (RON 71) boosted with ethanol appears to be the most promising combination for the OOD concept.

11 References

12

13 [1] ExxonMobil. The outlook for energy: A view to 2040; 2014

14 [2] U.S. Energy Information Administration. International energy outlook 2013. DOE/EIA-

15 0484(2013).

16 [3] BP energy Outlook 2030. Jan 2012

17 [4] World Energy Council London. Global Transport Scenarios 2050. 2011.

18 [5] International Energy Agency. World Energy Outlook 2011. 2011.

19 [6] G. Bourhis, JP. Solari, and R. Dauphin. Measurement of RON Requirements for Turbocharged SI Engines: One Step to the Octane on Demand Concept 2015. International Conference: SIA Powertrain - Versailles 2015 - 27-28 May 2015

22 [7] Rankovic N, Bourhis G, Loos M, and Dauphin R. Understanding octane number evolution for enabling alternative low RON refinery streams and octane boosters as transportation fuels,” Fuel, vol. 150, pp. $41-47,2015$. 
1 [8] Siemens PLM Automation https://www.plm.automation.siemens.com/fr_fr/products/lms/imagine-

2

4

5

6

7

8

9

10

11

12

13

14

15

16

17

18

19

20

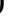
lab/automotive/index.shtml

[9] Dabadie JC., Menegazzi P., Trigui R., Jeanneret B. (2005) A new tool for advanced vehicle simulation, 7th ICE , Capri 2005 - SAE 2005-24-044

[10] JEC - Joint Research Centre-EUCAR-CONCAWE collaboration. Well-to-Wheels Report, Version 4.a.; 2014.

[11] Directive 2009/28/EC of the European Parliament and of the Council on the promotion and use of energy from renewable sources and amending and subsequently repealing Directives 2001/77/EC and 2003/30/EC; 2009.

[12] Christensen E, Yanowitz J, Ratcliff M, McCormick RL. Renewable oxygenate blending effects on gasoline properties. Energy Fuels 2011; 25:4723-33.

[13] Wu M, Wang M, Liu J, Huo H. Assessment of potential life-cycle energy and greenhouse gas emission effects from using corn-based butanol as a transportation fuel. Biotechnol Prog 2008; 24(6):1204-14. 


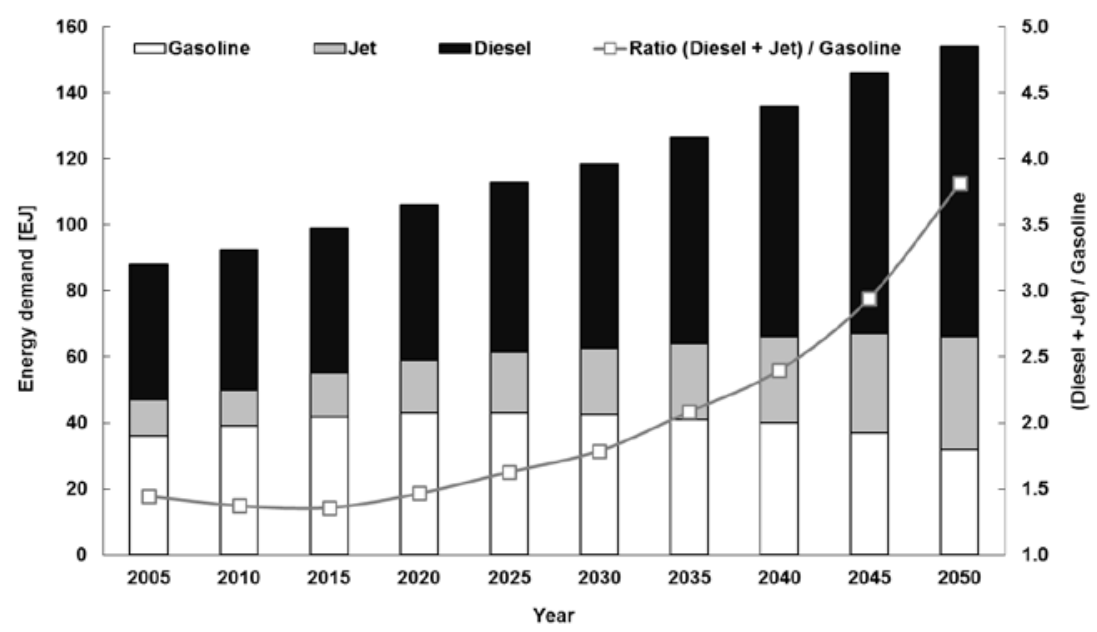

1

Fig. 1. Projected gasoline, jet fuel, and diesel demand (left axis, Exa Joules, $10^{18} \mathrm{~J}$ ), together with the ratio of middle-to-light distillates (right axis) from the World Energy Council Freeway Scenario 2050 [4]. 


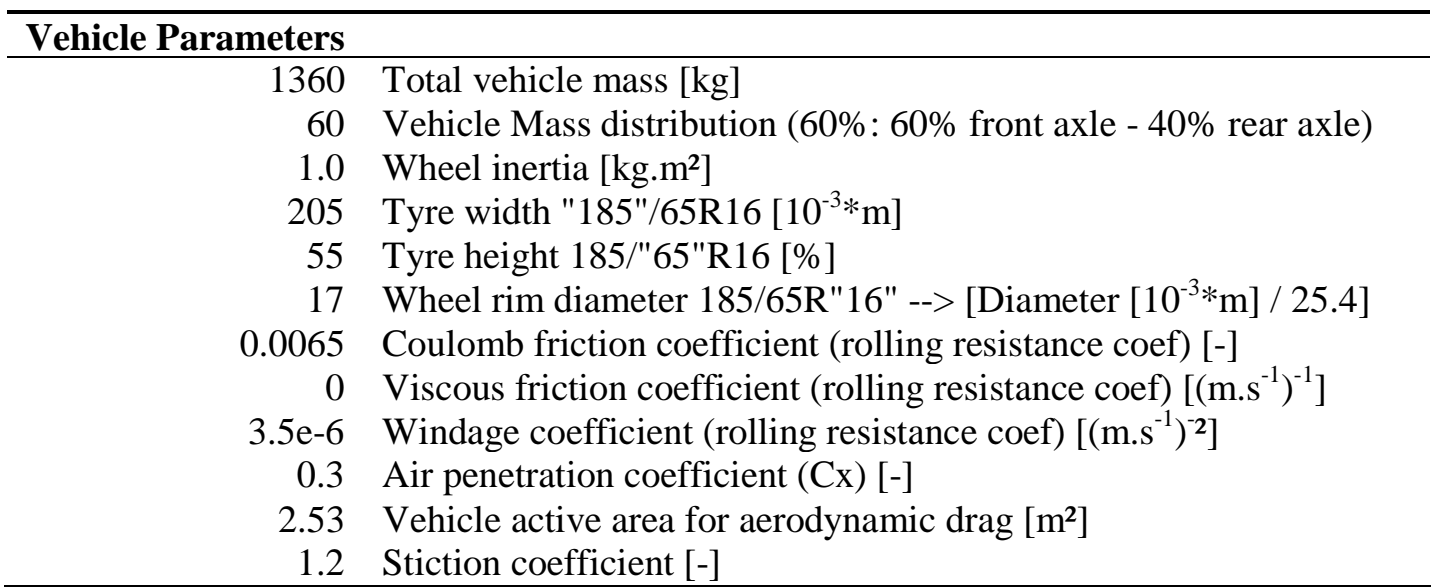




\title{
Gearbox parameters
}

\author{
71/17 Powered axle gear ratio [-] \\ 3.6532 Transmission gear ratio (1st gear) [-] \\ 1.9909 Transmission gear ratio (2nd gear) [-] \\ 1.2645 Transmission gear ratio (3rd gear) [-] \\ 0.8935 Transmission gear ratio (4th gear) [-] \\ 0.7288 Transmission gear ratio (5th gear) [-] \\ 0.6159 Transmission gear ratio (6st gear) [-] \\ Table 2 Simulator gear box parameters
}


1

2
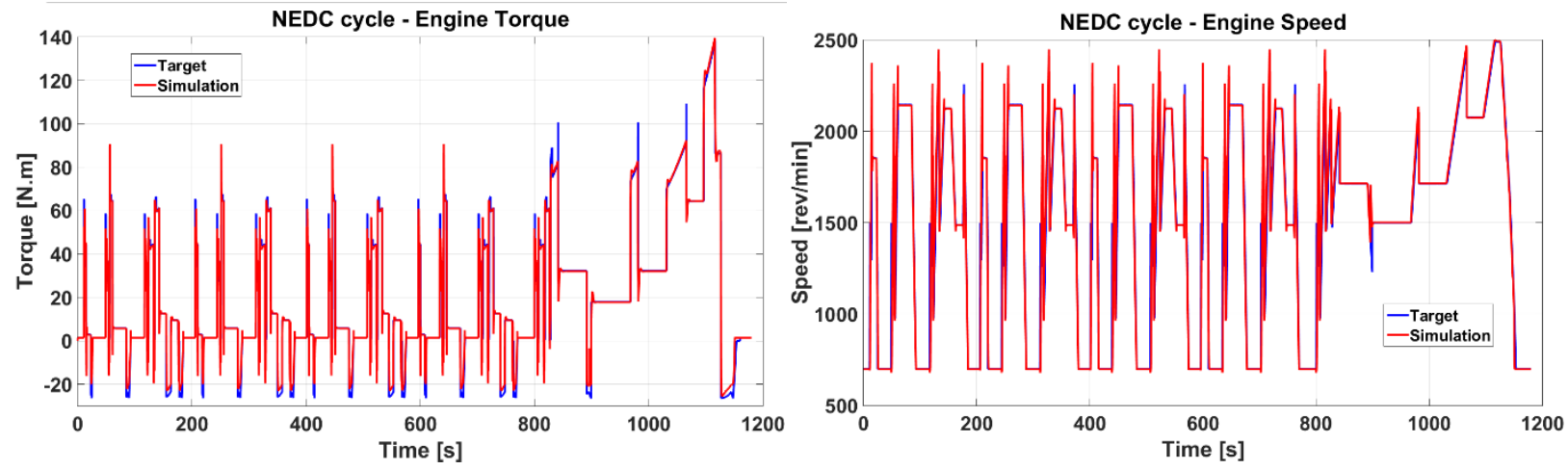

Fig. 2. Engine speed fitting and engine torque fitting on NEDC cycle

3


$5 \quad$ Fig 3 Amesim OOD vehicle simulator

6
7 
$\frac{1}{2}$ 3



4 5 6
Fig.4. NEDC cycle: a series of data points representing the speed of vehicle versus time

Fig. 5. WLTC cycle: a series of data points representing the speed of vehicle versus time 
1

\begin{tabular}{|c|c|c|}
\hline Engine CR & Base fuels & Octane boosters \\
\hline CR12:1 & Base fuel RON91 & Ethanol \\
\hline CR10.5:1 & Base fuel RON71 & Reformate \\
\hline CR7.5:1 & & SuperButol $^{\mathrm{TM}}$ \\
\hline & & DIB \\
\hline
\end{tabular}

2

3

Table 3 Base fuels, octane booster and compression ratios (CR) used in the present study 


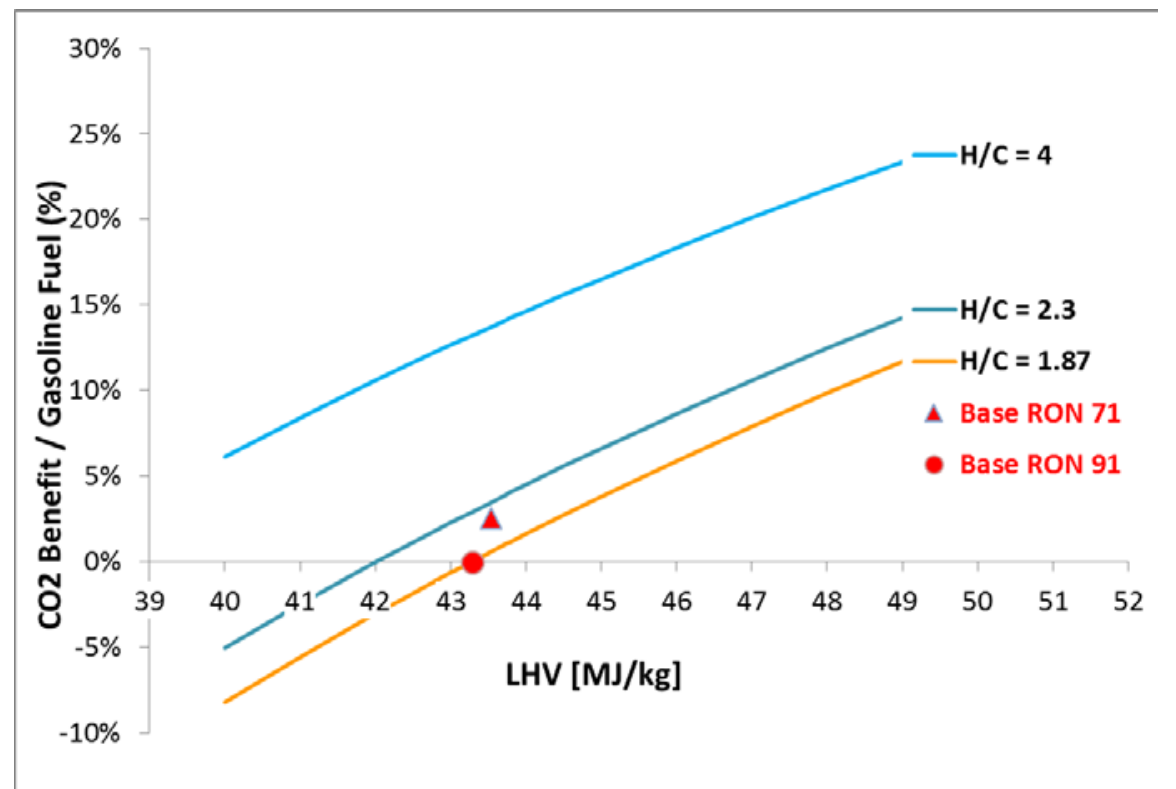

Fig. 6. Theoretical $\mathrm{CO}_{2}$ benefit (\%) / generic gasoline fuel and generic naphtha values versus $\mathrm{LHV}(\mathrm{MJ} / \mathrm{Kg}$ ) and $\mathrm{H}$ to $\mathrm{C}$ ratio of fuel. Dot and triangle mark represent respectively Base RON 91 and RON 71 used in the present work. 


\begin{tabular}{|c|c|c|c|c|c|c|}
\hline Stream Name & $\begin{array}{l}\text { RON } 91 \\
\text { Base Fuel }\end{array}$ & $\begin{array}{c}\text { RON } 71 \\
\text { Base Fuel }\end{array}$ & Reformate & Ethanol & SuperButol $^{\mathrm{TM}}$ & DIB \\
\hline Stream composition & $\begin{array}{l}\text { Non- } \\
\text { oxygenated } \\
\text { RON } 91 \\
\text { gasoline }\end{array}$ & $\begin{array}{c}\text { 56/44 vol. \% } \\
\text { naphtha/RON } \\
91 \text { Base fuel }\end{array}$ & $\begin{array}{l}\text { Catalytic } \\
\text { reforming unit } \\
\text { product }\end{array}$ & $\begin{array}{l}\text { High purity } \\
\text { ethanol, } \\
\text { water } \\
\text { content: } 200 \\
\text { mg/kg } \\
\end{array}$ & $\begin{array}{l}\text { Mixture of } \\
\text { butanol isomers } \\
\text { with a minor } \\
\text { DIB fraction }\end{array}$ & $\begin{array}{l}\text { 2,4,4-trimethyl-1- } \\
\text { pentene and } 2,4,4- \\
\text { trimethyl-2- } \\
\text { pentene } \\
\text { (3.75:1 mass ratio) }\end{array}$ \\
\hline RON & 91 & 71 & 111 & 108 & 107 & 104 \\
\hline LHV m [MJ/kg] & 43.28 & 43.54 & 41.17 & 26.95 & 36.35 & 43.67 \\
\hline LHV v [MJ/L] & 32.25 & 32.13 & 35.69 & 21.39 & 29.16 & 31.49 \\
\hline Density [g/cm3] @15² C & 0.745 & 0.738 & 0.867 & 0.794 & 0.802 & 0.721 \\
\hline Molar weight $[\mathrm{g} / \mathrm{mol}]$ & 94.1 & 99.3 & 103.6 & 46.0 & 75.2 & 111.7 \\
\hline $\mathrm{H} / \mathrm{C}$ & 1.9 & 2.0 & 1.3 & 3.0 & 2.5 & 2.0 \\
\hline O/C & 0.0 & 0.0 & 0.0 & 0.5 & 0.2 & 0.0 \\
\hline $\mathrm{g}\left[\mathrm{CO}_{2}\right] / \mathrm{g}[$ Fuel $]$ & 3.2 & 3.1 & 3.3 & 1.9 & 2.4 & 3.1 \\
\hline $\mathrm{g}\left[\mathrm{CO}_{2}\right] / \mathrm{MJ}[$ Fuel $]$ & 73.2 & 72.2 & 80.6 & 71.0 & 66.3 & 71.9 \\
\hline
\end{tabular}

1

Table 4. Analysis of base fuels and octane boosters used in the present study 

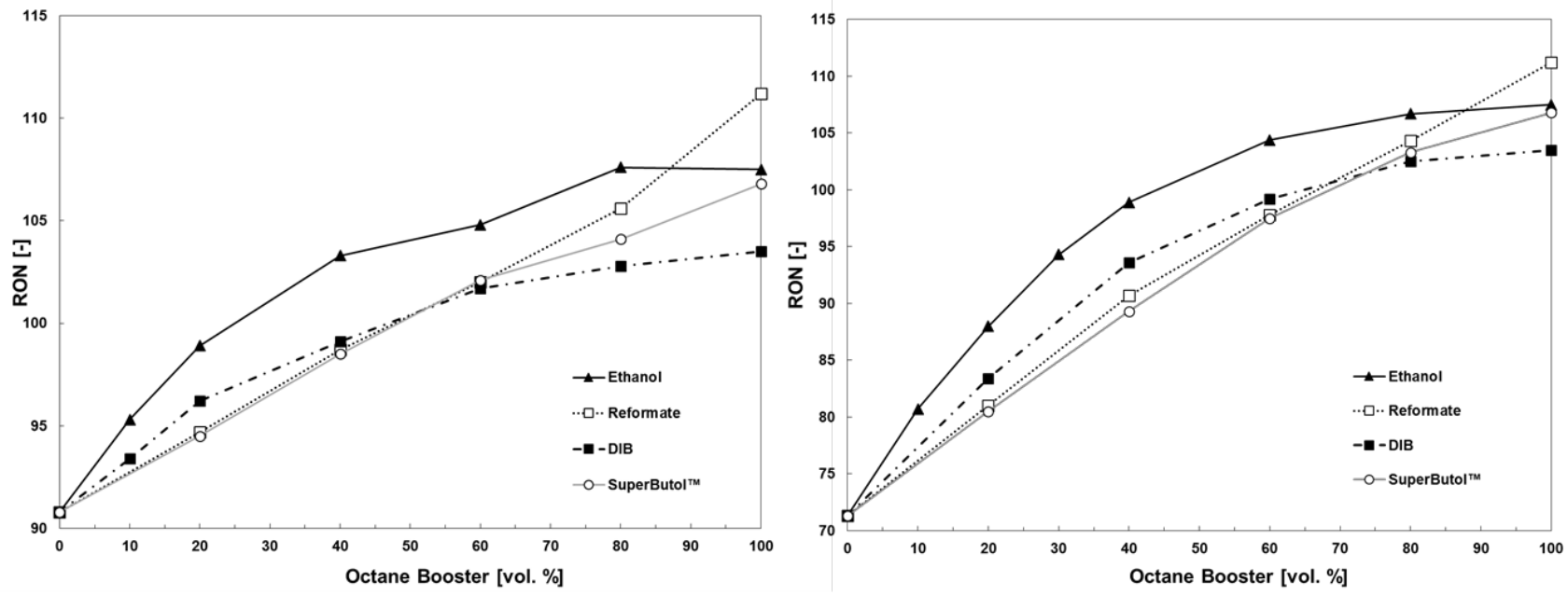

Fig. 7. Experimental RON value for blending booster with RON 91 base fuel (left) / with RON71 (right) plotted as a function of the booster volumetric incorporation rate 




Fig. 8. RON requirement map built with TRF at CR7.5:1 (black dots represents engine operating points over the NEDC cycle)



Fig. 9. RON requirement map built with TRF at CR 10.5:1 - stock configuration (black dots represents engine operating points over the NEDC cycle) 


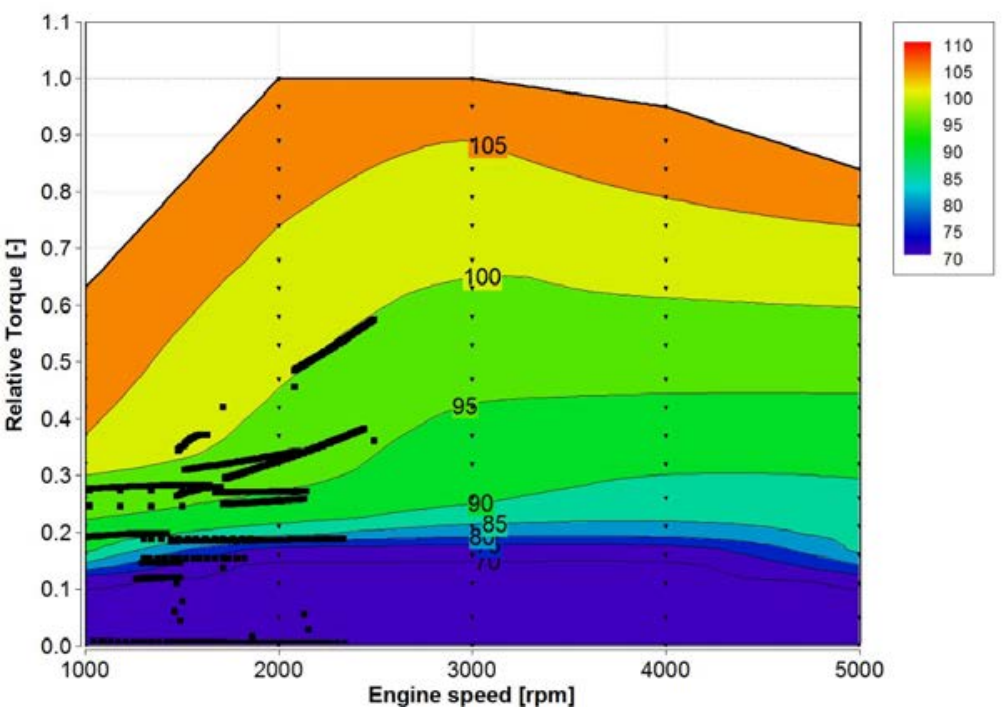

Fig.10. RON requirement map built with TRF at CR 12:1(black dots gives the speed and load over the NEDC cycle) 

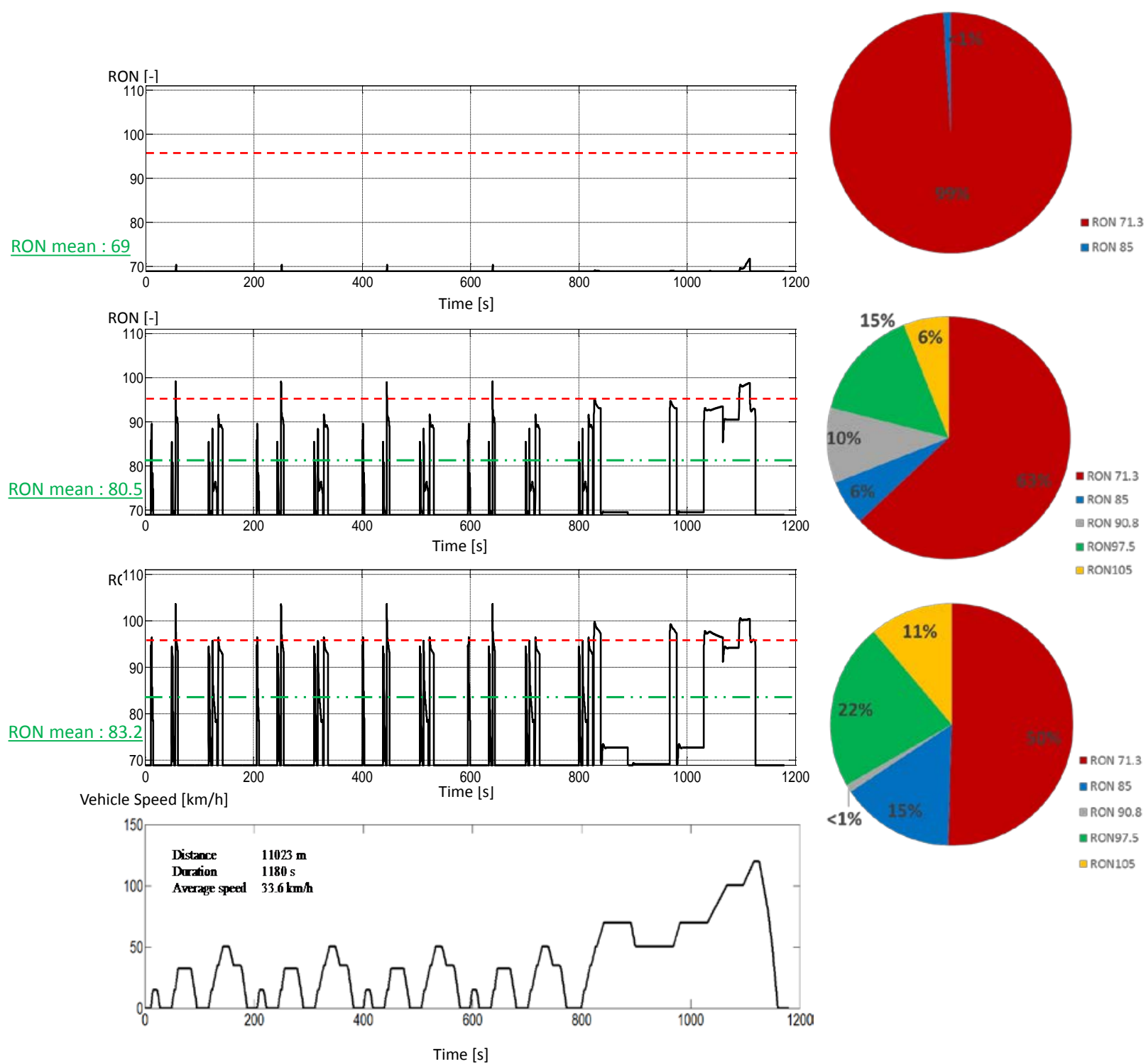

RON97.5

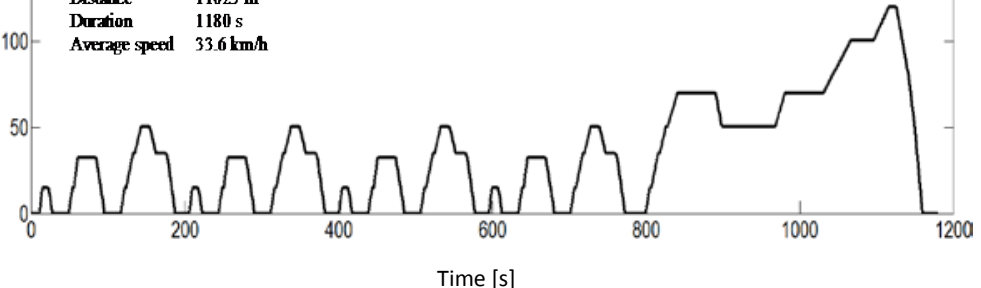

Fig. 11 Engine octane requirement for three different compression ratios (CR7,5:1 top - CR10.5:1 middle CR12:1 bottom) over NEDC cycle

Time graph: Instantaneous fuel octane requirement. RON 95 of standard commercial gasoline is represented by the red dashed line. The green dashed lines depict the volume average of the octane requirement. Pie graph: \%vol of octane requirement over the NEDC cycle 

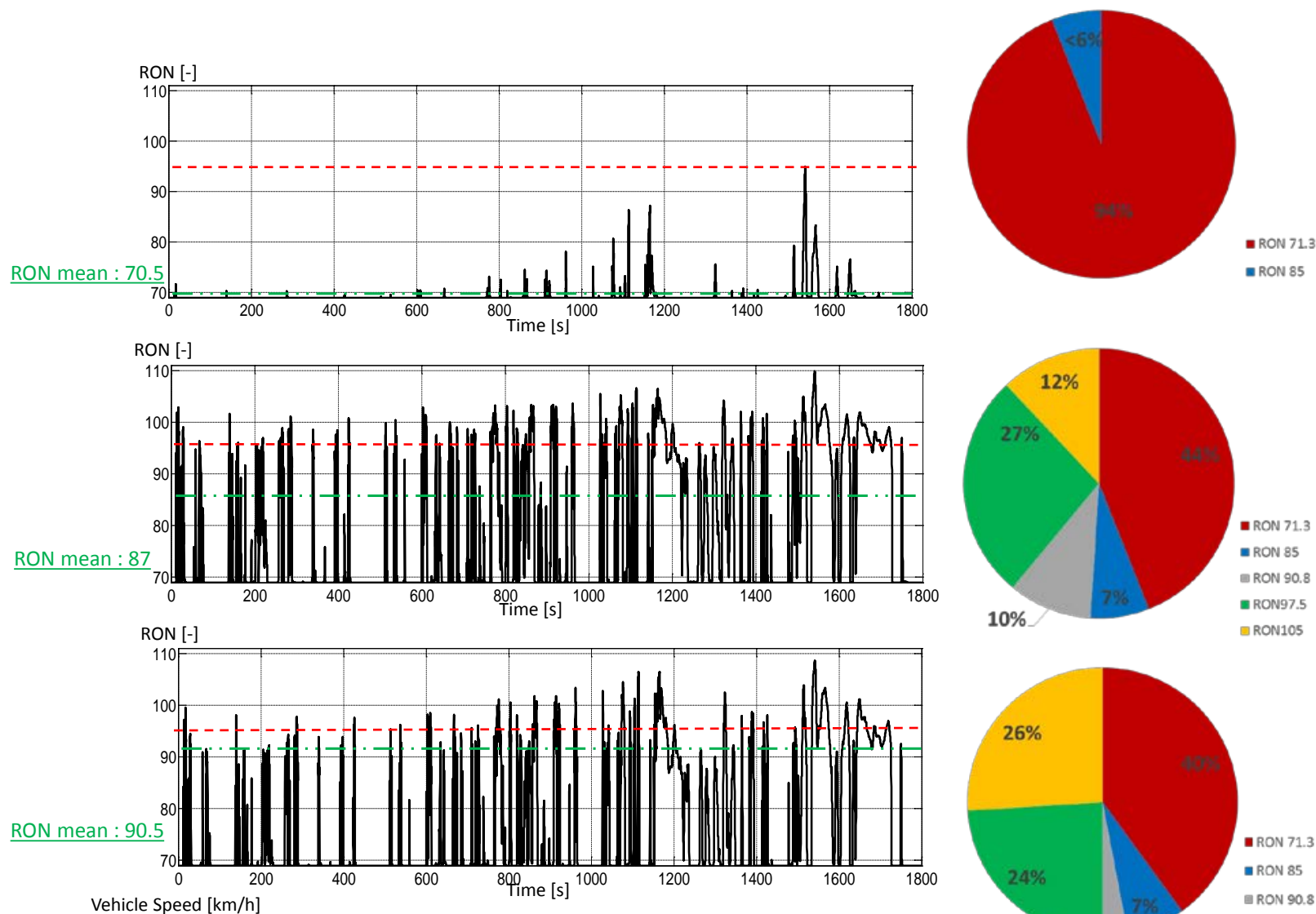

Vehicle Speed $[\mathrm{km} / \mathrm{h}]$
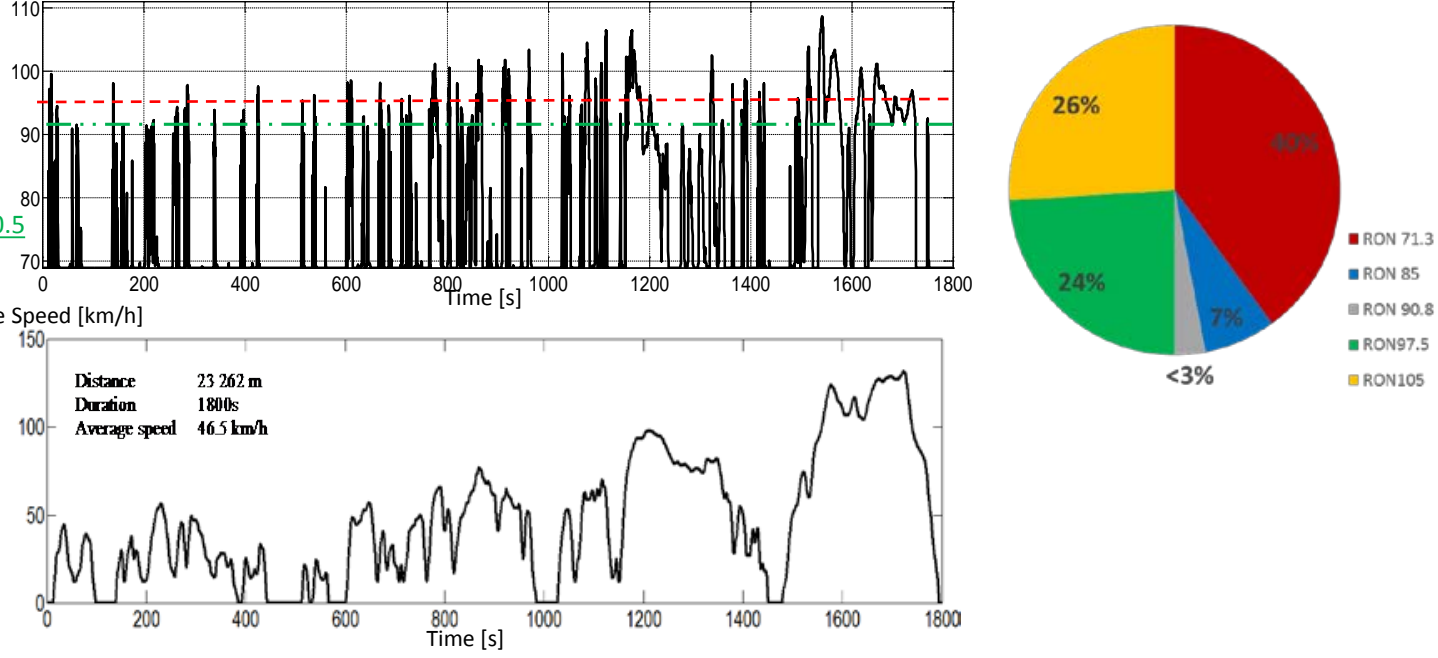

Fig. 12. Engine octane requirement for three different compression ratios (CR7,5:1 top - CR10.5:1 middle CR12:1 bottom) over WLTC cycle

Time graph: Instantaneous fuel octane requirement. RON 95 of standard commercial gasoline is represented by red dash line. The green dashed lines depict the volume average of the octane requirement. Pie graph: \%vol of octane requirement over the WLTC cycle 

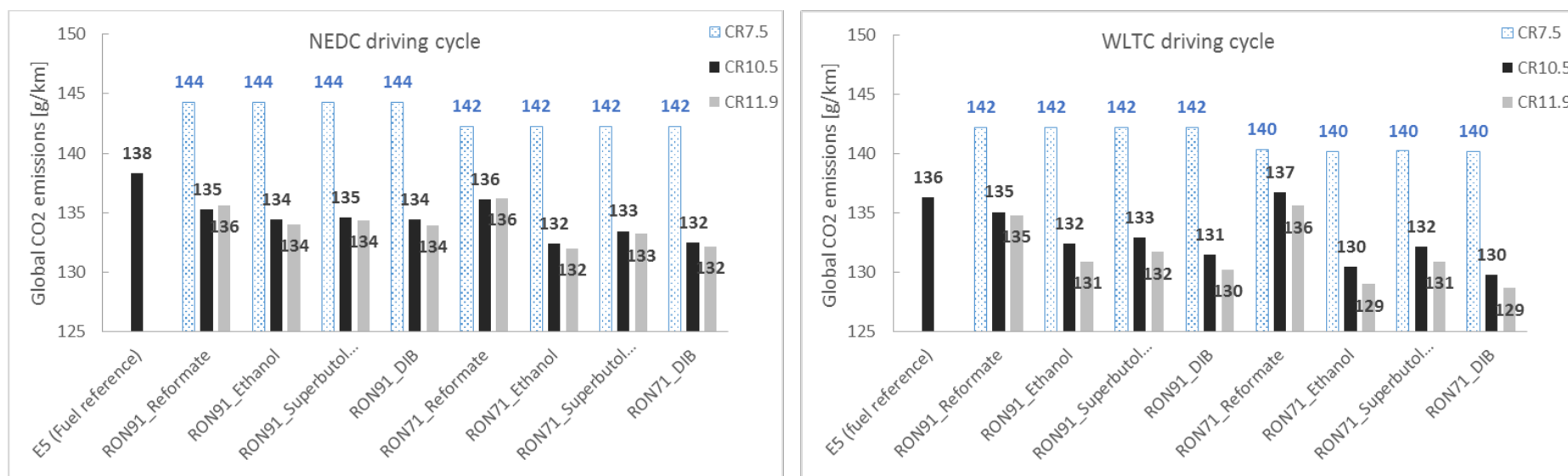

Fig. 13. Global $\mathrm{CO}_{2}$ emissions for all dual fuel combination and E5 (fuel reference), and the three different compression ratios (CR7.5, CR10.5, and CR12). Left panel: NEDC cycle, right panel: WLTC cycle 


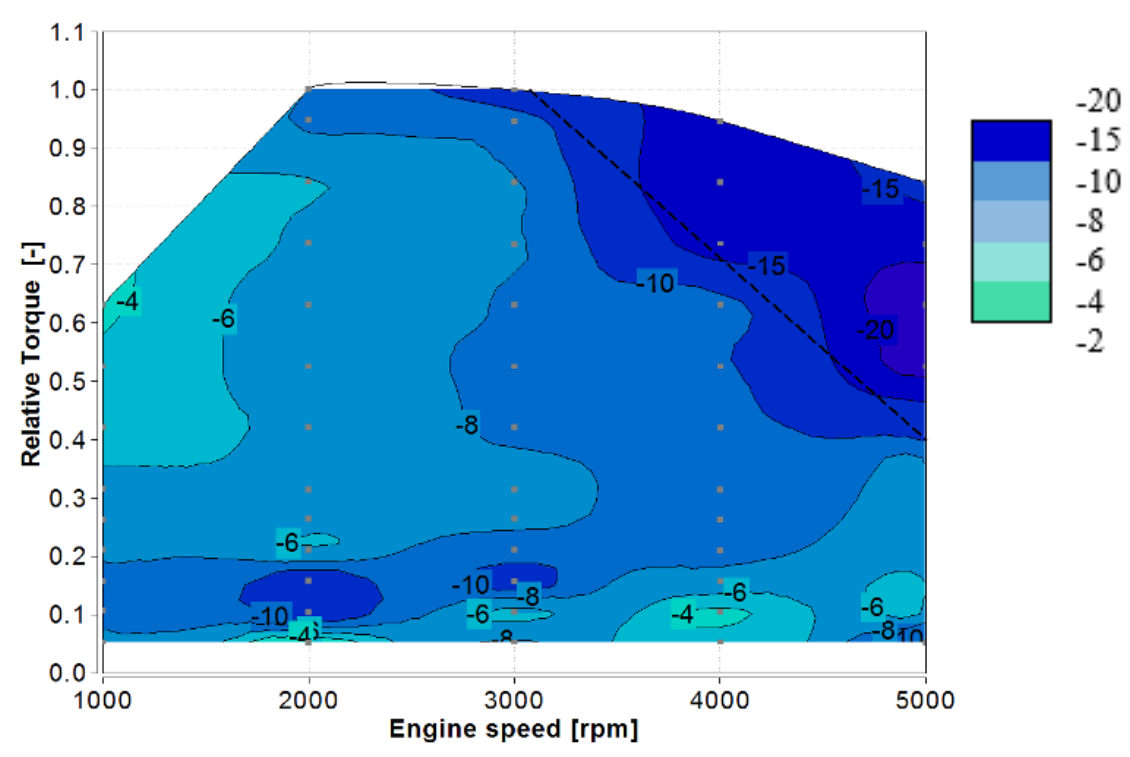

Fig. 14. Map representing BSFC gap between at CR7.5:1 and BSFC at 10.5:1 (Blue <=> BSFC $10.5<$ BSFC 7.5)

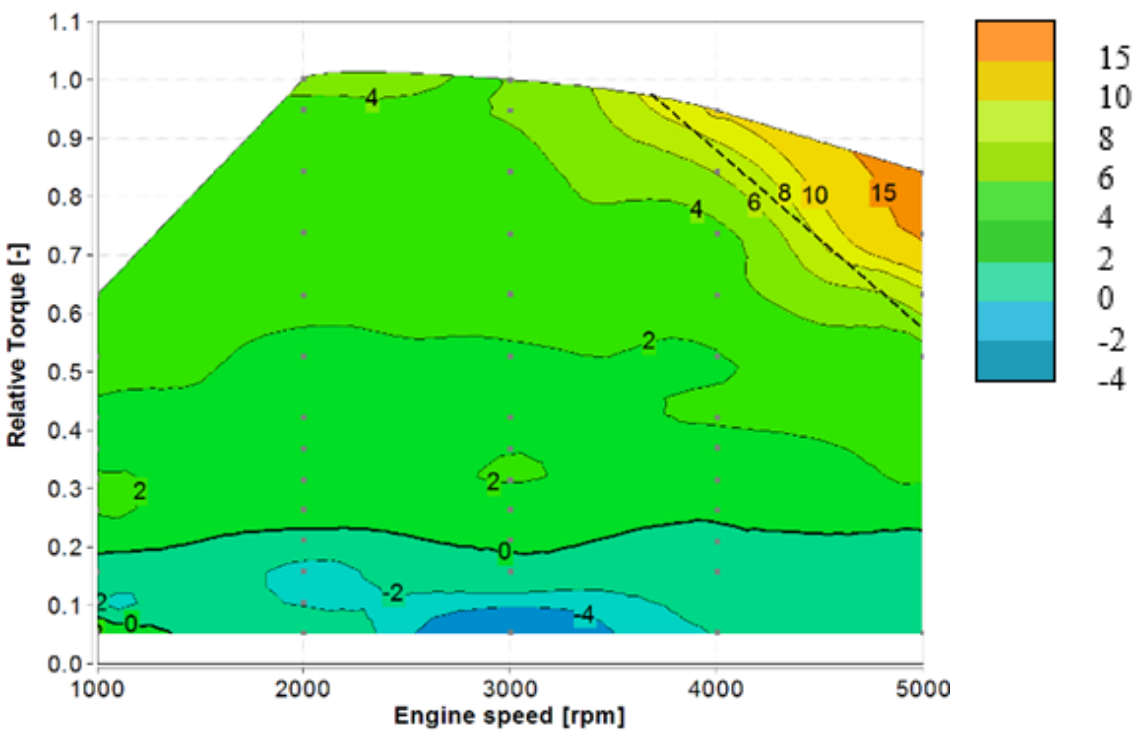

Fig. 15. Map representing BSFC gap between at CR12:1 and CR10.5:1 (from green to orange <=> BSFC $12<$ BSFC 10.5) 

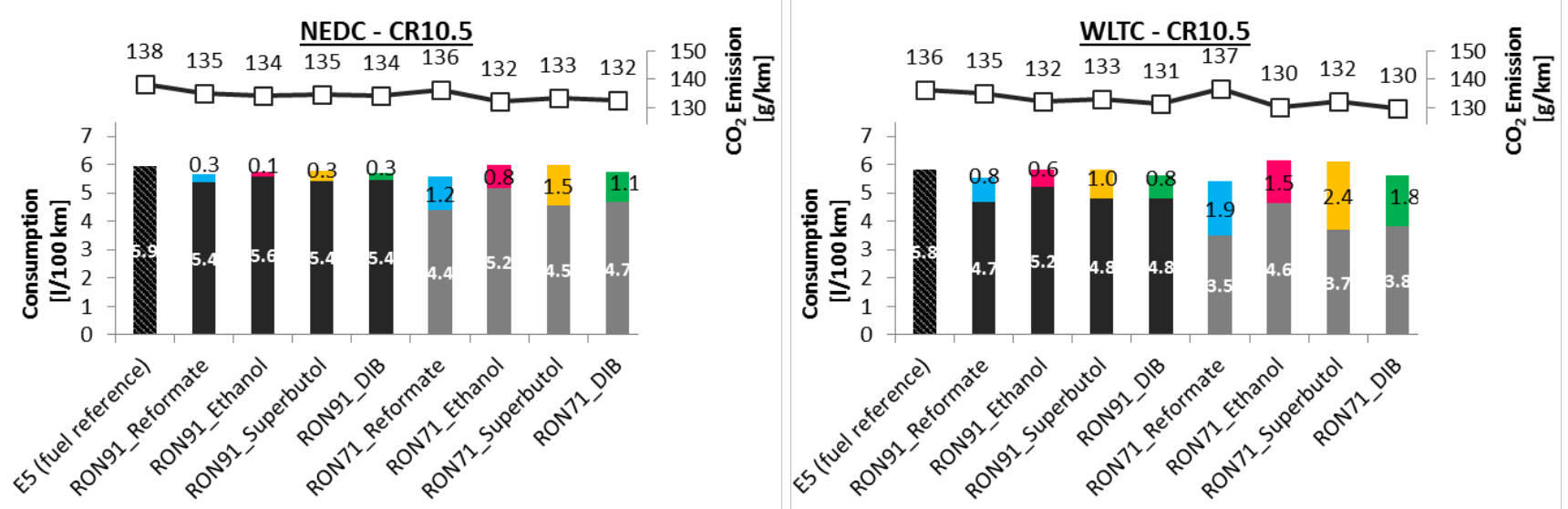

Fig. 16. Consumptions and CO2 emissions of base fuel and octane boosters and E5 (fuel reference) over NEDC (right) and WLTC (left).

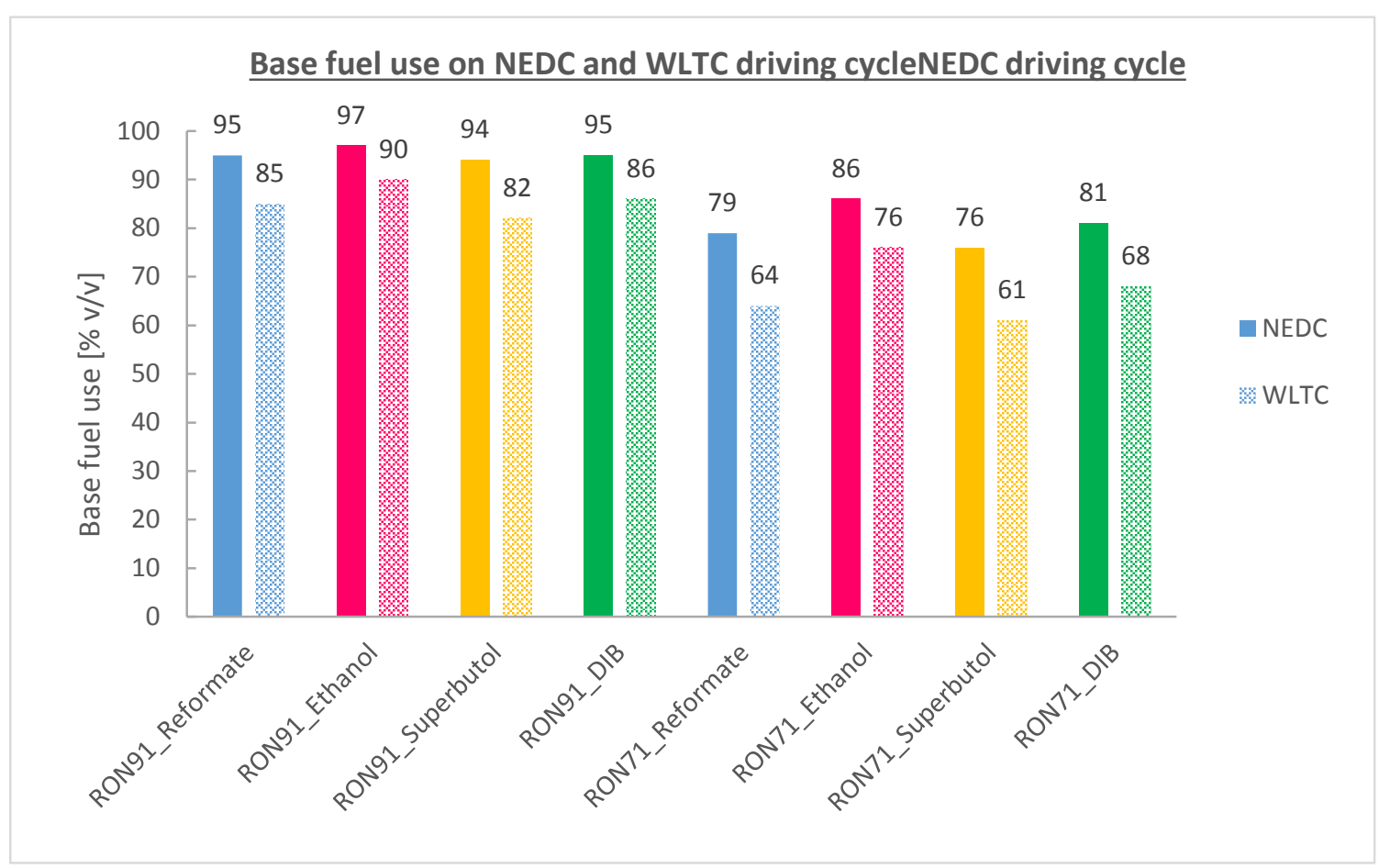

Figure 17 Comparison of bse fuel use on NEDC and WLTC driving cycle for each couple of fuels [\% $/ \mathrm{v}]$ 


\section{$1 \quad$ Glossary \\ 2}

3 BSFC: Brake Specific Fuel Consumption

4 CFR: Cooperative Fuel Research

5 CR: Compression Ratio

6 DI: Direct Injection

7 DIB: a mixture of 2,4,4-trimethyl-1-pentene and 2,4,4-trimethyl-2-pentene

8 FCC: Fluid-Catalytic-Cracking

9 GDI: Gasoline Direct Injection

10 IFP: Institut Français du Petrole

11 LHV: Lower Heating Value

12 MBTE: Maximal Break Torque Efficiency

13 MON: Motor Octane Number

14 NEDC: New European Driving Cycle

15 NOG: Non oxygenated Gasoline

16 OECD: Organization for Economic Co-operation and Development

17 OOD: Octane On Demand

18 PID: Proportional-Integral-Derivative regulator

19 RON: Research Octane Number

20 TRF: Toluene Reference Fuels

21 WLTC: Worldwide harmonized Light duty driving Test Cycle

22 
Reviewer/Editor comments:

\section{Reviewer \#1:}

This paper describes a OD vehicle simulator for identifying the best combination of base fuel, octane booster, and engine compression ratio, and it uses $\mathrm{CO} 2$ emissions and octane booster consumption as evaluation criterions. Results are interesting. However, there are problems in this manuscript. This manuscript may be acceptable for publication in Fuel after significant improvement.

1. Abstract should be rewritten; too much introduction in abstract should be avoided. Some key words should also be removed. I completely reduced and modified the former abstract. I hope that this introduction will be more acceptable for you.

2. $\mathrm{CO} 2$ emission is not the only parameter needed to be considered, other parameters including vapor pressure, flash point, corrosive properties should be also considered.

I completely understand your point of view. Effectively, all this parameter should be investigated but at a later stage of a project development. This is not the case here, we are focusing on a very advanced engineering concept close to TRL3.

3. The writing of the manuscript can be improved to make it more concise and clear. We rearranged part of the script.

4. Some errors as following:

In Page 10, line 18, "Reformate (RON)" is the first octane boosters which should be listed as NO.1, and line 23, "Ethanol" is the second one. Yes, sorry for this mistake, I corrected it. Thank you for this note. In Fig. 4 (Page 26), the distance, duration and average speed should be listed as Fig. 3 Yes, sorry for this mistake, I corrected it. Thank you for this note.

In Fig. 12 (Page 35), the proportion of base fuels and octane boosters should be declared. In Page 14, line 22, "BSFC" should be defined as an abbreviation for the first time. Yes, sorry for this mistake. I corrected it and created a glossary with all the abbreviations.

In Page 14, line 21, "When increasing the CR 7.5 to 10.5, significant decreasing of CO2 emissions are reported ( $8 \mathrm{~g}$ average)", please give some references. The figure was mentioned up in the text, but as it was not clear I mentioned the reference Line21 as well.

In Fig. 13 and Fig. 14, please illustrate the meaning of these colors. Yes I agree. I added color captions explaining the color equivalences

In Page 15, line 19, "Fig. 16 represents the percentage of booster use on each driving cycle for each couple of fuels." Please illustrate the final RON of these global fuel. Thanks for reporting this point, however I do not fully understand your expectation. Actually, we cannot illustrate the final RON of this global fuel as the RON is fully related to the engine requirement over the time. So, the fuel RON value matches the fuel requirement of the engine. It is the same for all fuels couples. This is just the rate of fuel baseline and booster for each couple that change over the time to meet the RON requirement.

In summary, this paper may be acceptable for publication in Fuel after the above comments/concerns have been addressed. 
Reviewer \#2: The paper is suitable for publication with minor amendments the work is novel, a useful contribution to knowledge and I am not aware of similar work in the literature.

The Title could be condensed. We considered your input. A new appealing title is then suggested.

It seems that the base fuel octane has been predetermined rather than emerging from the calculations. Yes, that's pretty much correct. Actually, the RON91 base fuel corresponds to the current RON baseline prior to mixing with ethanol to get RON95E5. The RON 71 base fuel was elected considering strategic view of the company and based on previous internal studies.

The term "CO2" is used several times without explaining whether tailpipe or well-to-wheels emissions are referred to. Yes, effectively you are right, I precised "CO2 tailpipe emission" in the abstract and introduction sections. Then, I did not repeat each time to avoid awkwardness.

Reducing tailpipe $\mathrm{CO} 2$ emissions through adjustments to the $\mathrm{H} / \mathrm{C}$ ratio is a trivial result, since the carbon is simply emitted elsewhere. The focus should be on the improvements possible to engine efficiency using the boosted octane. For the scope of this paper, we reported that we have $4.5 \%$ of $\mathrm{CO} 2$ benefits with OOD concept when to conventional engine using E5. Further optimizations regarding the right downsizing/ upsizing of the engine altogether its design itself are currently leading to better improve $\mathrm{CO}_{2}$ benefits and reduce booster consumption.

The 71RON + boosted is an alternative fuels approach for most of the world which presents a large barrier to implementation. Recognizing that this is a scoping study, some mention should be made of using the lowest octane available in major world regions e.g. EuroSuper 95RON - what benefits would be possible in that case? Thank you for asking this relevant question. However, considering that the boosting effect of ethanol is less important when increasing the RON value of the base fuel, we do not expect to change significantly the RON value of the blend between [RON91/ethanol] and [RON95/ethanol]. So, as a result, we do not expect to have significant difference of $\mathrm{CO} 2$ when using RON95/ethanol when compared [RON91/ethanol]. As a pure assumption we should be around $0.1-$ $0.2 \% \mathrm{CO}_{2}$ benefit.

The simulation technique needs more description, at least a brief step by step explanation of the calculation, plus a reference to a more detailed description, or a more detailed explanation is a reference is not available. I agree and the part has been modified and is more detailed now. I hope this is more understandable now.

p17 reference to unpublished work seems premature: the statement that octane requirement could be reduced is only meaningful if a statement is made about retaining efficiency. I understand and consequently, I removed the unpublished reference.

A glossary would be helpful. Done, I added a glossary. Please, excuse me for this oversight.

The text is fairly clear throughout, however I would suggest a review of the language for conciseness and clarity.

All script has been re modified and re read. I hope this is clearer now. 